\title{
Distal locking in femoral intramedullary nailing system: Is one cross screw sufficient?
}

\author{
Saravana Vail Karuppiah", Alan Johnstone Johnstone
}

Orthopaedic Unit, Woodend Hospital, Aberdeen, UK

Email: saravanavail@yahoo.com

Received 31 May 2012; revised 4 July 2012; accepted 10 September 2012

\section{ABSTRACT}

Introduction: The indications for intramedullary nail fixation of fractures of the femoral shaft have been greatly expanded by techniques of interlocking nailing. However, distal locking screw fixation remains the most technically demanding and problematic portion of the procedure and maybe responsible for as much as one-half of the exposure of the surgeon's hands to radiation during the procedure. Objective: This biomechanical study was undertaken to compare the stability of using one distal locking cross screw versus two cross screws in femoral fractures fixed with intramedullary nailing (IMN) system. Materials: A composite model made from a stainless steel IMN $(12 \mathrm{~mm} \times 1 \mathrm{~mm})$ was connected to a load cell (Instron machine). Axial forces upto $2 \mathrm{kN}$ (3 times body weight) was applied or until a maximum displacement of $1 \mathrm{~mm}$ was reached. The distal locking end of the intramedullary nail was secured with stainless steel cylinders of different dimensions $50 \mathrm{~mm} \times 5 \mathrm{~mm}$, $75 \mathrm{~mm} \times 5 \mathrm{~mm}$ and $100 \mathrm{~mm} \times 3 \mathrm{~mm}$ to represent the proximal femoral diaphysis, diaphyseo-metaphyseal junction and distal femoral metaphyseal respectively. The distal locking end of the intramedullary nail was attached to the cylinder with a dedicated single or two rods $(5 \mathrm{~mm}$ diameter), made from stainless steel, to represent the distal locking cross screw. Results: In the $50 \mathrm{~mm}$ cylinder, the mean stiffness ( \pm standard deviation) of the system using either single or two screws were similar i.e. $3298 \pm 144 \mathrm{~N} / \mathrm{mm}$. But in the $75 \mathrm{~mm}$ and $100 \mathrm{~mm}$ cylinders, the mean stiffness of the fracture model with two distal locking cross screws fixation was $2.059 \pm 96 \mathrm{~N} / \mathrm{mm}$ and $0.816 \pm 122$ $\mathrm{N} / \mathbf{m m}$ and with single distal locking cross screw fixation were $0.643 \pm 142 \mathrm{~N} / \mathrm{mm}$ and $0.289 \pm 88 \mathrm{~N} / \mathrm{mm}$ respectively. Conclusion: Single distal locking cross screw fixation provide poorer fracture stability compared to two distal locking cross screws when used to fix distal femoral metaphyseal fractures.

${ }^{*}$ Corresponding author.
Keywords: Femoral Nail; Two Cross Screws; Biomechanics Study; Stability of Fracture

\section{INTRODUCTION}

The use of cross screws have revolutionised the treatment of long bone fractures with intramedullary nails. Screws placed both proximally and distally to the fracture provide precise anatomical reconstruction while maintaining the length of the bone. Its use has enabled early mobilization and weight bearing of patients with even significant comminuted fractures [1-3].

The proximal and distal interlocking screws provide sufficient axial and tensional forces rigidity and allow the patient to move without the risk of shortening or malrotation. However, distal locking fixation, using two cross screws, may be responsible for as much as one-half of the exposure of the surgeon's hands to radiation during the procedure $[4,5]$. Some studies have shown, one distal locking screw is sufficient to provide adequate stability compared to two distal locking screws there by reducing the duration of surgery and surgeons exposure to radiation $[6,7]$.

However in femoral fracture fixation, the length of the distal cross screws varies depending at the point of fixation in the distal femoral fractures. The anatomy of the distal femur may influence the length of the cross screw used in distal locking. We hypothesize that there maybe a variable stiffness on the intramedullary nailing system depending on the length and number of distal locking cross screws.

In the current study, a biomechanical investigation was undertaken to examine if one distal cross screw was sufficiently stable compared to two distal cross screws in femoral fractures fixed with intramedullary nailing system.

\section{OBJECTIVE}

This biomechanical study was undertaken to compare the effectiveness of using one distal locking cross screw versus two cross screws in femoral fractures fixed with 
intramedullary nailing (IMN) system.

\section{MATERIALS AND METHODS}

\subsection{Materials}

The intramedullary nails were simulated using stainless steel tubes with a length of $150 \mathrm{~mm}$, outside diameter of $12 \mathrm{~mm}$ and inside diameter of $11 \mathrm{~mm}$. These dimensions were similar to intramedullary nails used surgically. The distal bone end of the femoral bone was simulated using stainless steel cylinders and sawbones. In the study three different cylinders were used to represent different parts of the femur, with the dimensions comparable to clinical measurements using $x$-rays:

- Outside diameter $50 \mathrm{~mm}$, wall thickness $5 \mathrm{~mm}$, height $50 \mathrm{~mm}$ (proximal diaphyses bone with a narrow canal and a thick cortical wall);

- Outside diameter $75 \mathrm{~mm}$, wall thickness $5 \mathrm{~mm}$, height $50 \mathrm{~mm}$ (metaphyseal junction);

- Outside diameter $100 \mathrm{~mm}$, wall thickness $3 \mathrm{~mm}$, height $50 \mathrm{~mm}$ (distal condylar bone with a wide canal and a thin cortical wall).

The hole in the cylinder was $25 \mathrm{~mm}$ and $35 \mathrm{~mm}$ from the top end of the cylinder for the proximal hole of the distal nail and distal hole respectively.

\subsection{Methods}

An Instron 1822 materials testing machine (Instron Ltd., High Wycombe, UK) was used for mechanically testing the intramedullary nails. A customised stainless steel clamp was designed to connect the proximal portion of the intramedullary nail to the cross-head of the testing machine. The stainless steel cylinder, which represented the femur, was attached to the base of the testing machine. The distal end of the intramedullary nail was secured to the cylinders with $\operatorname{rod}(\mathrm{s})$; this represented the cross screw. In the test, representing a single distal cross screw fixation, the proximal hole of the distal IMN was use. The test set-up is shown in (Figure 1). Similarly for test representing two distal cross screws, both the distal holes of the IMN was used.

The intramedullary nail was subjected to an axial compressive load, by lowering the cross-head of the testing machine; the load was applied at a rate of $0.05 \mathrm{~N} / \mathrm{s}$. During the testing load and displacement were recorded. Testing continued until a maximum displacement of 1 $\mathrm{mm}$ or a maximum force of $2 \mathrm{kN}$ was reached. A displacement of $1 \mathrm{~mm}$ was chosen, as a fracture will not heal if there is excessive deflection, and typical amplitudes during walking have been measured to be about 1 $\mathrm{mm}$ [8]. A load of $2 \mathrm{kN}$ represents about three times body weight, load transferred across the knee, for a $70 \mathrm{~kg}$ individual when walking [9]. Each test configuration was

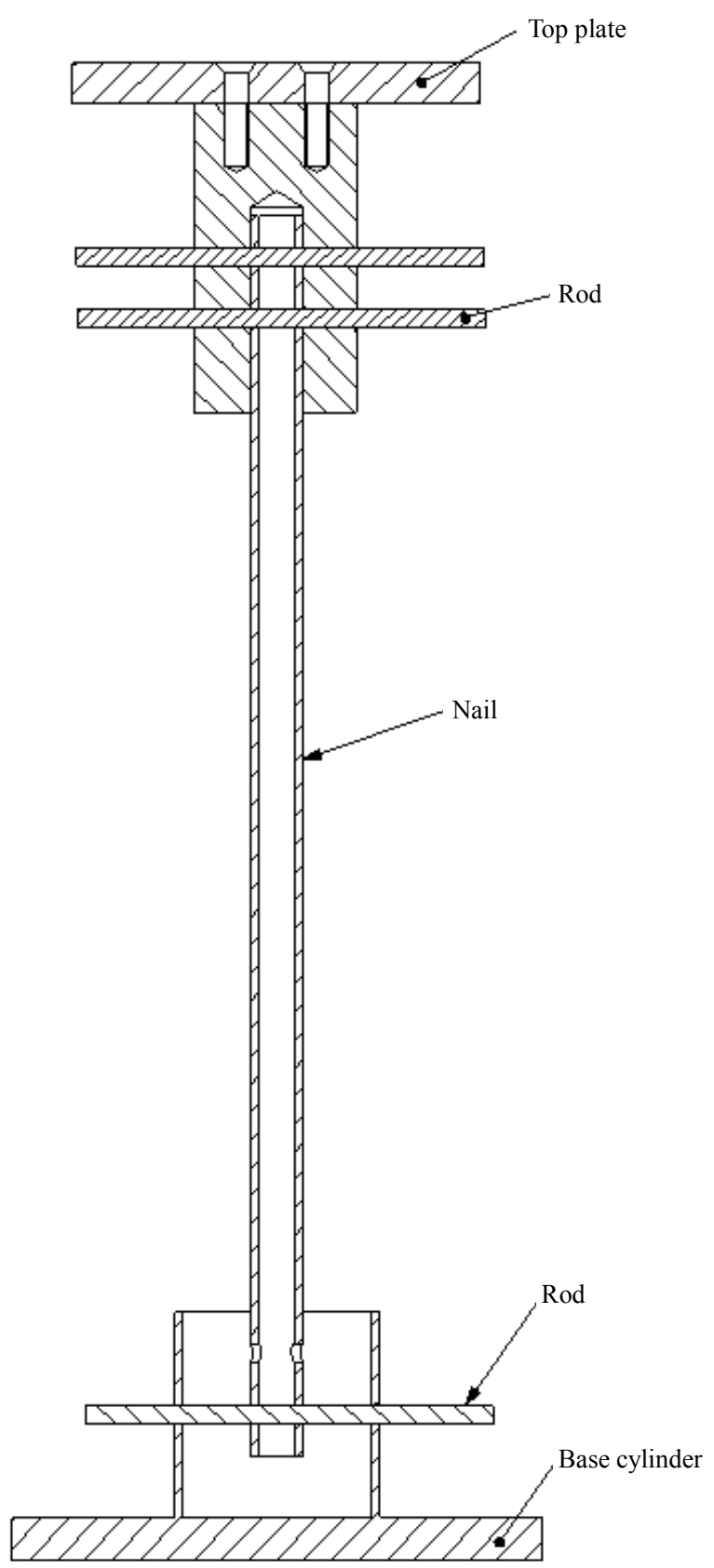

Figure 1. Test set-up with intramedullary nail attached proximally to Instron machine with a top plate using a rod. Distally the nail is attached with a single or two rod(s) representing distal locking screw(s) to variable size cylinders on the base plate.

tested three times for each various size cylinders made from Stainless steel cylinder. Maximum force of failure was also recorded for each cylinder.

Graphs of load against displacement were plotted (Figure 2 shows a typical example) and a forth-order polynomial fitted to the results. The stiffness was then determined from the gradient of the graph at a displacement of $0.5 \mathrm{~mm}$. 


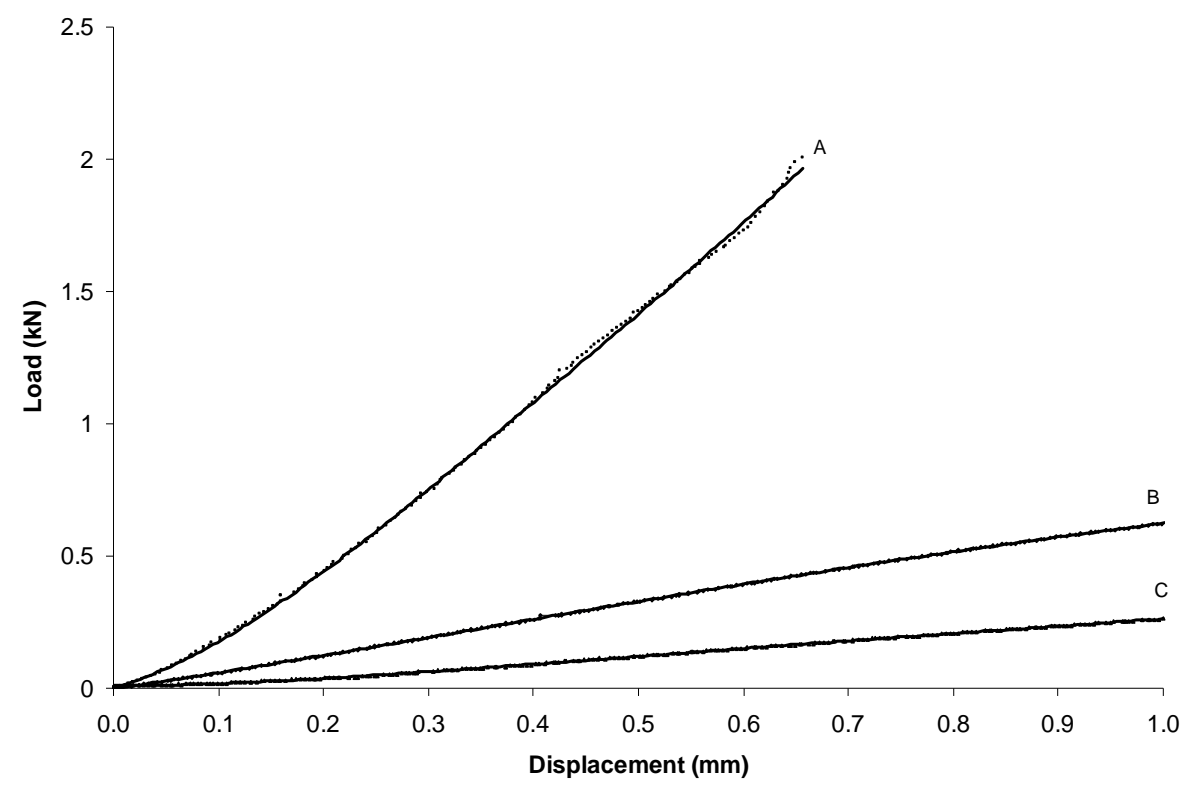

Figure 2. Graphs of load against displacement for a cylinder of outside diameter: (A) $50 \mathrm{~mm}$. Curve fit $y=7.1293 x^{4}-11.956 x^{3}+7.7119 x^{2}+1.0647 x+0.0035, R^{2}=0.9995$; (B) $75 \mathrm{~mm}$. Curve fit $y=0.1341 x^{4}-0.4407 x^{3}+0.3588 x^{2}+0.5726 x-0.0012, R^{2}=0.9999$; (C) $100 \mathrm{~mm}$ Curve fit $y=0.2709 x^{4}-0.7248 x^{3}+0.6727 x^{2}+0.0352 x+0.0091, R^{2}=0.9998$. The calculated mean stiffness for $50 \mathrm{~mm}$ (A) cylinder is stronger then mean stiffness for $100 \mathrm{~mm}$ (C) cylinder using single rods. The mean stiffness improves with two rods in the in the $75 \mathrm{~mm}$ cylinder.

\section{RESULTS}

In the $50 \mathrm{mmmm}$ cylinder, the mean stiffness ( \pm standard deviation) of the system using either single or two screws were similar ie $3298 \pm 144 \mathrm{~N} / \mathrm{mm}$. But in the $75 \mathrm{~mm}$ and $100 \mathrm{~mm}$ cylinders, the mean stiffness of the fracture model with two distal locking cross screws fixation was $2.059 \pm 96 \mathrm{~N} / \mathrm{mm}$ and $0.816 \pm 122 \mathrm{~N} / \mathrm{mm}$ and with single distal locking cross screw fixation was $0.643 \pm 142$ $\mathrm{N} / \mathrm{mm}$ and $0.289 \pm 88 \mathrm{~N} / \mathrm{mm}$ respectively.

\section{DISCUSSION}

Various study have investigated into the influence of the number of cross screws that is required for optimal fixation of the femora fractures using femoral nailing system [10]. Most studies have shown that there is no difference between the use of one or two distal locking [7] cross screws and both had similar results and stability in axial and torque forces. In this study, similar to previous studies, have shown similar results using either one or two cross screws used to fix at the diaphyseal (screws length $50 \mathrm{~mm}$ ). However longer screws used to fix at metaphyseal $(75 \mathrm{~mm})$ and supracondylar $(100 \mathrm{~mm})$ had variable results between one and two distal cross screw fixation.

The principle aim of fracture fixation is to provide stability of the bone fragments and restoration of normal anatomy. Intramedullary nails act as a scaffold and are devised to hold together the proximal and distal ends of the long bone for a conducive environment for fracture healing.

The proximal (diaphyseal) femoral canal is narrow in which the intramedullary nail has a "snug fit" against the bone. Hence, the inter bone-nail distance is minimal or none. With increasing bone diameter, the distal condylar part of the femur, there is a wide canal and a thin cortex. Longer cross screws are required to fix metaphyseal and distal femoral fractures. In this study, it has been shown that in the femoral fractures fixed at diaphysis, with either one or two distal cross screws, have similar axial stiffness. With longer cross screws, used in the distal and extreme distal fractures, one screw fixation was less stable compared to two distal cross screw fixation. This is due to the increased cross screw length as shown in previous study [11].

In the clinical situation, when the patient bears weight the greater the diameter of the canal, the greater the deflection will be.

\section{REFERENCES}

[1] Bick, E.M. (1968) The intramedullary nailing of fractures. Clinical Orthopaedics \& Related Research, 60, 5-12.

[2] Brumback, R.J., Toal, T.R., Murphy-Zane, M.S., Novak, V.P. and Belkoff, S.M. (1999) Immediate weight-bearing after treatment of a comminuted fracture of the femoral shaft with a statically locked intramedullary nail. Journal 
of Bone \& Joint Surgery, 81, 1538-1544.

[3] Schatzker, J. (1998) Fractures of the distal femur revisited. Clinical Orthopaedics \& Related Research, 347, 43-56.

[4] Goulet, J.A., Londy, F.R.T., Saltzman, C.L. and Matthews, L.S. (1992) Interlocking intramedullarynails: An improved method of screw placement combining image intensification and laser light. Clinical Orthopaedics \& Related Research, 281, 199-203.

[5] Levin, P.E., Schoen, R.W. and Browner, B.D. (1987) Radiation exposure to the surgeon during closed interlocking intramedullary nailing. Journal of Bone \& Joint Surgery, 69A, 761-766.

[6] Grover, J. and Wiss, D.A. (1995) A prospective study of fractures of the femoral shaft treated with a static, intramedullary, interlocking nail comparing one vs two distal screws. Orthopedic Clinics of North America, 26, 139-146.

[7] Hajek, P.D., Bicknell, H.R., Bronson, W.E., Albright, J.A. and Saha, S. (1993) The use of one compared with two distal screws in the treatment of femoral shaft fractures with interlocking intramedullary nailing: A clinical and biomechanical analysis. Journal of Bone \& Joint Surgery,
77, 519-525.

[8] Gardner, T.N., Evans, M., Hardy, J. and Kenwright, J. (1997) Dynamic interfragmentary motion in fractures during routine patient activity. Clinical Orthopaedics \& Related Research, 336, 216-225. doi:10.1097/00003086-199703000-00030

[9] Taylor, S.J., Walker, P.S., Perry, J.S., Cannon, S.R. and Woledge, R. (1998) The forces in the distal femur and the knee during walking and other activities measure by telemetry. The Journal of Arthroplasty, 31, 428-437. doi:10.1016/S0883-5403(98)90009-2

[10] George, C.J., Lindsey, R.W., Noble, P.C., Alexander, J.W. and Kamaric, E. (1998) Optimal location of a single distal interlocking screw in intramedullary nailing of distal third femoral shaft fractures. Journal of Orthopaedic Trauma, 4, 267-272. doi:10.1097/00005131-199805000-00009

[11] Karuppiah, S.V., Johnstone, A.J. and Duncan, D.E.T. (2010) How cross screw length influences the stiffness of intramedullary nailing systems. Journal of Biomedical Science and Engineering, 3, 35-38. doi:10.4236/jbise.2010.31005 